\title{
Examining the Relationship between Parental Educational Expectations and a Community-Based Children's Savings Account Program
}

Emily Rauscher ${ }^{1}$, William Elliott ${ }^{1}$, Megan O’Brien ${ }^{1}$, Jason Callahan ${ }^{2}$ and Joe Steensma ${ }^{3}$

${ }^{1}$ Center on Assets, Education, and Inclusion

University of Kansas

www.aedi.ku.edu

${ }^{2}$ Superintendent, Wabash City Schools

${ }^{3}$ Professor of Practice, Public Health and Social Entrepreneurship, George W. Brown School of Social Work, Washington University in St. Louis

\section{Acknowledgments}

AEDI is indebted to the staff of Promise Indiana for their invaluable guidance in pulling together this report. Particular acknowledgement is owed to: Clint Kugler, Amanda Jones-Layman, and Phil Maurizi.

\section{Funding}

This work was supported by the Lilly Endowment Inc. [Grant number 2015-0644] and the Charles Stewart Mott Foundation [Grant number 2012-0059]. These organizations are not responsible for the quality or accuracy of the report, which is the sole responsibility of AEDI, nor do they necessarily agree with any or all of the report's findings and recommendations.

(C) 2017. This manuscript version is made available under the CC-BY-NC-ND 4.0 license http://creativecommons.org/licenses/by-nc-nd/4.0/ 


\begin{abstract}
This paper presents evidence of the relationship between exposure to a community-based Children's Savings Account (CSA) program and parents' educational expectations for their children. We examine survey data collected as part of the rollout and implementation of The Promise Indiana CSA program. Although results differ by parental income and education, results using the full sample suggest that parents are more likely to expect their elementary school-age children to attend college if they have a 529 account or were exposed to the additional aspects of the Promise Indiana program (i.e., the marketing campaign, college and career classroom activities, information about engaging champions, trip to a University, and the opportunity to enroll into The Promise). Parents who were both exposed to the additional aspects of the Promise Indiana program and have a 529 account are over three times more likely to expect their child to attend college than others, increasing to 13 times more likely among parents with no college education. Overall, results suggest a community-based CSA program - Promise Indiana - is associated with nontrivial benefits for families.
\end{abstract}

\title{
Keywords
}

Educational expectations; inequality; college savings; quantitative analysis; community intervention 


\section{Introduction}

Education spurs economic growth and innovation, promotes health, and expands skilled and higher-paying jobs that demand more educated workers (Lutz et al. 2008; Lutz and Samir 2011; Rauscher 2015). Educational expansion has become more critical for economic growth and job creation in the context of what some call the "knowledge economy" (Powell and Snellman 2004), when production relies more on intellectual resources than on physical or natural resources (Coomans 2005; Lutz et al. 2008; Hooks et al. 2010). Parental educational expectations, defined as parents' realistic predictions about their children's future academic achievements (Briley, Harden, \& Tucker-Drob, 2014; Elliott \& Sherraden, 2013; Wang \& Benner, 2014), are critical for children’s educational achievement and attainment (Kim, Sherraden, \& Clancy, 2013; Wang \& Benner, 2014; Benner \& Mistry, 2007; Elliott, 2009; Wang \& Benner, 2014; Wells, Seifert, \& Saunders, 2013). Thus, increasing parental expectations may be crucial to help increase educational attainment.

Children’s Savings Accounts (CSAs) are one potential policy lever that could increase parental educational expectations. A growing body of research examines the relationship between CSAs and multiple outcomes, including parental educational expectations for their children (Kim, Sherraden, Huang, \& Clancy, 2015), but also children’s social and emotional development (Huang, Sherraden, Kim, \& Clancy, 2014), children’s and parents’ college-saver identity development (Elliott, 2015), and maternal well-being (Huang, Sherraden, \& Purnell, 2014). Other research has independently discovered effects of assets-including those held in account vehicles and in amounts comparable to CSAs_-on academic achievement (Elliott, Jung, \& Friedline, 2011), educational attainment (Elliott, 2013; Elliott \& Beverly, 2011), and later financial well-being (Friedline, 2014). While this collective evidence base supports the utility of 
children's savings as an investment in educational outcomes, the field currently lacks thorough examination of the relative contributions of different CSA design features to these measures. For example, there is some evidence of the effectiveness of state- or city-level CSA programs in influencing college expectations and educational preparation (Kim, Sherraden, Huang, \& Clancy, 2015), but little is known about how a community- or county-level CSA program - involving schools, community organizations, local philanthropists, and banking institutions - may be related to educational expectations among parents. Although research has found effects of a CSA program with a $\$ 1,000$ initial deposit (Kim, et al., 2015), policymakers facing budget constraints may need to know whether a much smaller initial deposit of $\$ 25$ is similarly associated with increases in parental expectations for their children.

In an effort to address these knowledge gaps, we collect and examine data on the implementation of a CSA program in four counties in Indiana. This CSA program, called Promise Indiana, brings together school districts, convening organizations (in some cases, the YMCA; in other communities, key roles are played by school districts, county economic development agencies, United Ways, and/or community foundations), and the state 529 planIndiana CollegeChoice (Kugler, personal communication January 7, 2015; Jones-Layman, personal communication May 12, 2015).

In addition to the facilitation of college saving through various programmatic features, the Promise Indiana model also hinges on activation of community champions whose contributions—-financial and otherwise—aim to support children's educational attainment. Promise Indiana's model and implementation approach have been refined as the CSA has been rapidly replicated in other Indiana communities. As more states develop CSA programs, 
evidence of the effects of various types of CSA models can inform policymakers working to increase children’s opportunities.

\section{Background on Child Savings Accounts}

Michael Sherraden (1991) introduced the concept of Child Savings Accounts (CSAs) in his seminal book, Assets and the Poor. ${ }^{1}$ While sometimes conflated with the state 529 savings plans on which many are built, CSAs are interventions distinct from this account infrastructure, and they work on several fronts to alter children's educational trajectories. In accordance with Sherraden's conceptualization, CSAs provide children and families with an initial 'seed' deposit to spark asset accumulation. The amount of the initial deposit for most programs ranges from $\$ 25$ to $\$ 1,000$, with smaller amounts typically serving the purpose of paying initial fees required to open the 529s and larger deposits serving to more vigorously catalyze asset accumulation. CSAs also incorporate matching funds and incentives, which add public or philanthropic funds to families’ savings in order to extend meaningful savings incentives, support balance-building of lower-income savers, and parallel the supports already available to higher-income households through tax benefits (Woo, Rademacher, \& Meier, 2010).

The notion of Children's Savings Accounts as outlined by Sherraden (1991) is less about achieving a particular outcome such as increased college enrollment and more about how to build assets among lower-income children and families in pursuit of greater equity across the lifespan. CSAs were envisioned as "savings accounts that provide financial access, information, and incentives to encourage lifelong asset building and promote child development” (Huang,

\footnotetext{
${ }^{1}$ Sherraden (1991) originally referred to CSAs as Child Development Accounts, or CDAs. However, they are more commonly known today in the media and by Promise Indiana as Children's Savings Accounts (CSAs), and so here, we have chosen to use CSAs.
} 
Sherraden, Kim, \& Clancy, 2014, p. E2). The initial vision for these accounts called for a range of allowable purposes, including education, homeownership, and other development (Sherraden, 1991). As such, they are sometimes referred to as Child Development Accounts (CDAs). From this perspective, in order to be considered a CSA, an initiative must:

- Provide some financial information/education

- Bridge families' access to financial products and services

- Seed accounts with an initial deposit

- Provide incentives for saving, often including matches

While Sherraden's vision originally included broad asset purposes, in more recent years, CSAs have been designed more specifically as savings vehicles for helping families and children begin planning for college early, loosely situated within the educational institution as part of states' or municipalities' college-going and financial aid strategies. As a result, what constitutes a CSA has evolved somewhat to encompass features that not only help children and families build assets but also help them develop a college-going orientation.

Unlike some other financial aid tools like student debt, which may actually reduce the return on college (for a review of some of this research, see Elliott \& Lewis, 2015), thereby compromising education's equalizing effect, CSAs and education appear to enhance the capacity of one another to act as economic mobility agents. For instance, evidence suggests that CSAs are associated with children's educational attainment (AEDI, 2013), which itself is a conduit of economic mobility (Butler, Beach, \& Winfree, 2008). Therefore, we suggest linking CSAs to human capital development may be one of the best ways to maximize the power of both for restoring the promise to all people of being able to achieve economic mobility if they work hard. Interventions that augment education's capacity as the primary path to economic mobility may 
be particularly significant given growing murmurs that college may not be paying off like it once did (Bennett \& Wilezol, 2013), even while the lifetime 'cost' of failing to continue one’s education is nearly twice what it was two generations ago (Greenstone \& Looney, 2011).

With greater focus on CSAs as part of their college-going strategies, a number of states are adopting specific outreach and engagement approaches to cultivate an orientation to early college saving as a mechanism through which to increase educational attainment (e.g., Lewis \& Elliott, 2015). For example, after streamlining uptake of the initial \$100 deposit into the 529 available to all babies born in Rhode Island, the state is now implementing an outreach approach designed to take advantage of this gateway to college saving. These efforts, begun shortly after a child's birth, include welcome packets, media campaigns, and alliances throughout the educational system to increase awareness of Rhode Island's CSA and to further develop positive educational expectations among both children and parents. Similar efforts are underway in Maine, which provides a larger initial seed to all children born to state residents and then uses regular account statements and age-appropriate educational materials to further strengthen educational expectations. Promise Indiana, the focus of this paper, provides a more comprehensive example of how CSAs can be designed to better achieve their college-going objectives and how, in many cases, state 529 plans can be modified to align with this mission.

\section{Project Description}

At its core, Promise Indiana's model assumes that communities can be activated to empower families to plan, prepare, and at least partially pay for their children’s future education. The model further advances the idea that supporting children in the development of an early college-bound identity is not the sole responsibility of parents, but that each child in a 
community deserves and can benefit from the mobilization of champions who provide financial resources and social encouragement of children’s educational aspirations (see Lewis \& Elliott, 2015 for more details on the early history and development of the Promise Indiana CSA design and evolution).

Based on personal communication with key architects (Kugler, January 7, 2015; JonesLayman, May 12, 2015) and review of Promise Indiana materials, we gathered information about the program design. Promise Indiana represents a collaboration among various community groups, including the Wabash County YMCA, local philanthropists, financial institutions (UPromise/Ascensus, Indiana Education Savings Authority or IESA), and schools. The program facilitates the opening of youth CollegeChoice accounts at school registration events and includes classroom activities to expose children to college and careers. Promise Indiana seeks to provide children and families not only with opportunities and support to open accounts and the concrete financial resources with which to pay for college, but also the college-saver identities that accrue through the account ownership experience. Significantly, while the Children's Savings Account aspect of Promise Indiana is 'opt-in', requiring parental account opening, many of the other features that may support the development of parental and child educational expectations are delivered universally to all children attending participating schools. For example, while the typical CSA program usually only consists of an account, match, and incentives, Promise Indiana includes components that have not traditionally been included in CSA programs such as college and career readiness activities and visits to local colleges.

The three original goals of Promise Indiana were to raise children's and parents' expectations about educational attainment, provide resources to place higher education within reach, and change behavior, through the cultivation of a community orientation to college 
savings and a college-going culture to support educational attainment. These goals shifted somewhat as the Promise Indiana team's understanding of the forces that shape children's educational trajectories evolved. However, this basic framework, emphasizing meaningful and facilitated access to savings vehicles, support for durable college-bound identities, and cultivation of financial behaviors associated with later economic well-being, still informs the measures by which Promise Indiana’s success is gauged. From its origins in Wabash County (with seven schools), Promise Indiana was subsequently implemented in three additional counties in the 2014-2015 school year (27 schools) and four additional counties in the 2015-2016 school year (52 schools). In each case, key stakeholders in these additional counties were encouraged to consider their efforts as a 'launch' in their respective communities, not a replication of the Promise Indiana model; for example, some school districts used online registration rather than in-person. Moreover, Promise Indiana architects provided extensive materials and training to support implementation, an approach that both eases the burden on new partners and increases fidelity to the model.

\section{Review of Research on Parental Educational Expectations}

Because raising educational expectations was a central goal of Promise Indiana, we focus on that outcome in this study. Parents are an influential force in their children's educational trajectories, particularly through their expectations for their children’s future academic achievement. Evidence indicates that parental educational expectations, defined as parents’ realistic predictions about their children’s future academic achievements (Briley, Harden, \& Tucker-Drob, 2014; Elliott \& Sherraden, 2013; Wang \& Benner, 2014), significantly influence children's motivation to succeed in school and move on to higher levels of education (Kim, 
Sherraden, \& Clancy, 2013; Wang \& Benner, 2014). Children whose parents hold high educational expectations for their futures tend to demonstrate more academic competency, earn higher grades and test scores, and attain higher levels of education than do students whose parents maintain low educational expectations, perhaps because parents' expectations motivate children to work harder in school (Benner \& Mistry, 2007; Elliott, 2009; Wang \& Benner, 2014; Wells, Seifert, \& Saunders, 2013) and/or because these parents provide supports that augment children’s own efforts. A comprehensive literature review by Yamamoto (2010) identifies mechanisms by which parental educational expectations influence children’s academic competency and performance, including by supporting children’s perceptions of their own academic capabilities and possible educational attainment, prompting parental involvement in children’s academic activities and behaviors, and influencing teachers’ perceptions of children’s academic capabilities, even acting as a buffer for low teacher expectations (Benner \& Mistry, 2007; Briley, Harden, \& Tucker-Drob, 2014). Research also indicates a reciprocal effect between parental educational expectations and children's academic achievement, as parents base their own expectations at least in part on their children's previous academic performance (Kim et al., 2013).

Furthermore, children internalize their parents’ educational expectations in a way that influences their own educational expectations for their futures and, in turn, their academic performance (Wang \& Benner, 2014, Benner \& Mistry, 2007, Kim et al., 2013). A longitudinal study (Rutchick, Smyth, Lopoo, \& Dusek, 2009) revealed a close association between the educational expectations of parents and children five years after the benchmark measure, even when controlling for demographic variables and children’s previous achievement scores, demonstrating the profound influence of parents' educational expectations on those of their 
children. However, this relationship is mitigated, to some extent, by children's interpretations of these parental plans, which, depending on parent-child interactions related to college and the future, may not match parents’ actual expectations (Wang \& Benner, 2014).

Across demographic categories, parents hold high educational expectations for their children, though these expectations do vary by race and ethnicity, socioeconomic status, and parents' educational attainment (Kim et al., 2013; Spera, Wentzel, \& Matto, 2009). Parents' experiences with education largely determine their ability to help children navigate the higher education and financial aid systems, influencing their predictions for whether their children will attend college. Socioeconomic status appears to be one of the strongest predictors of parental educational expectations. One study revealed a significant difference in educational expectations between parents with high and low household incomes, finding that about 50 percent of parents with household incomes of $\$ 25,000$ or less and about 87 percent of parents with household incomes of more than \$75,000 expect their children to attend college (Child Trends, 2010; Kim et al., 2013). In addition to financial barriers, parents with low socioeconomic status often lack access to information about college expenses and resources to plan for financing a college education, stunting parents' expectations that their children will reach college (Benner \& Mistry, 2007; Behnke, Piercy, \& Diversi, 2004; Kim, Sherraden, Huang, \& Clancy, 2015), particularly as their children age and college financing becomes a more urgent imperative.

\section{Research on Children's Savings Accounts}

There is evidence that CSA programs are associated with parent and child outcomes, including parental educational expectations. Particularly relevant for this study, evidence from the randomized control trial, SEED for Oklahoma Kids (SEED OK), examines the impact of a 
CSA on the durability of parents' educational expectations from birth to age four (Kim, Sherraden, Huang, and Clancy, 2015). They find that parents who are in the treatment group (receiving a CSA) have higher expectations for their children and that their expectations are more likely to remain constant or increase during this time period than those of parents in the control group. These effects are strongest for the poorest families (Kim, Sherraden, Huang, and Clancy, 2015). Also importantly, differences in the designs of the SEED OK CSA and of Promise Indiana raise questions about whether Promise Indiana's approach will produce similar results. For example, Promise Indiana includes the recruitment of community champions to support the development of a college-going culture and incorporates college and career readiness activities such as taking children to visit local colleges and share their own career goals. However, while SEED OK provides a \$1,000 initial deposit, Promise Indiana provides a much smaller initial deposit of $\$ 25$. Additionally, SEED OK begins at birth, while Promise Indiana accounts are usually opened at kindergarten registration. Given these important differences, there is a need to further examine the relationship between Promise Indiana participation and parental educational expectations in order to determine whether CSAs designed differently will still elicit similar effects on parental expectations.

\section{Research Questions}

In this paper, we seek to understand whether Promise Indiana is correlated with positive parental expectations by comparing levels of expectations before and after rollout of the program. Subgroup variations of particular interest include parents' education level and income. Specifically, our research questions are: 
1) After implementation of Promise Indiana, are parents more likely to expect their child to attend college?

2) Does the relationship between Promise Indiana and parental expectations vary by parental income and/or education?

\section{Methods}

Data. Data for this study come from the College and Career Planning Questionnaire, an anonymous 21-item paper-and-pencil survey developed by Promise Indiana program staff to gather information about college expectations and savings knowledge and activities. It includes questions about family demographics, educational expectations, and perceived barriers to secondary education, as well as savings behaviors and knowledge specifically about 529 college savings accounts.

Procedure. Pre-test questionnaires were administered in the spring semester prior to summer rollout of the Promise Indiana marketing campaign and program; post-test questionnaires were administered in the fall semester immediately following this campaign. By measuring parental expectations shortly before and after the program rollout, we limit other changes that may have occurred in the interim. This approach allows us to capture potential short-term changes in educational expectations. There may be long-term changes associated with the program, but further research would be required to address that question. The data were collected shortly before and after the program was first rolled out in each county, so families did not have previous exposure to the Promise program.

The College and Career Planning Questionnaire was sent home with all students in Kindergarten through $3^{\text {rd }}$ grade (Wabash, LaGrange, and Noble surveyed $\mathrm{K}$ - 3 while Whitley 
County surveyed only $\mathrm{K}$ and $1^{\text {st }}$ grade as their target cohort for The Promise intervention). A Promise Indiana representative delivered the surveys to the school and school staff or teachers distributed the surveys to each child, to be taken home and completed by parents. The survey packet contained a short explanatory note to families about the purpose of the survey and an empty envelope labeled "Wabash County Promise” (with the county name altered appropriately in other counties) for parents to return the survey.

Table 1 displays the data collection timeline and response rates. Pre-test questionnaires were administered during spring 2013 to parents of children in Wabash County. The same questionnaire was administered in spring 2014 to parents of children in LaGrange, Noble, and Whitley Counties, to coincide with Promise Indiana launch there.

Survey response rates were calculated based on enrollment numbers in Kindergarten through $3^{\text {rd }}$ grade in the schools surveyed. The intervention occurred one year earlier in Wabash County. 'Before Promise’ represents Spring 2013 in Wabash and Spring 2014 in all other counties. 'After Promise’ represents Fall 2013 in Wabash and Fall 2014 in all other counties.

Table 1. Data Collection Timeline and Response Rates by County $(N=3,060)$

\begin{tabular}{lcccc}
\hline & $\begin{array}{c}\text { Before Promise } \\
\text { Spring 2013 }\end{array}$ & $\begin{array}{c}\text { After Promise } \\
\text { Fall 2013 }\end{array}$ & $\begin{array}{c}\text { Before Promise } \\
\text { Spring 2014 }\end{array}$ & $\begin{array}{c}\text { After Promise } \\
\text { Spring 2014 }\end{array}$ \\
\hline Wabash $(n=685)$ & $18 \%$ & $28 \%$ & -- & -- \\
LaGrange $(n=784)$ & -- & -- & $15 \%$ & $35 \%$ \\
Noble $(n=1,241)$ & -- & -- & $33 \%$ & $23 \%$ \\
Whitley $(n=350)$ & -- & -- & $11 \%$ & $10 \%$ \\
\hline
\end{tabular}

Note. Response rates are estimates. Total enrollment (the denominator for each county) is based on NCES kindergarten-third grade enrollment before (2012-13) and after (2013-14) Promise in Wabash and before (2013-14) Promise in other counties. Total enrollment after Promise in LaGrange, Noble, and Whitley Counties is drawn from NCES data for the previous year (201314, assumed to remain the same in 2014-15) because data are not yet available for the 2014-15 academic year. Private school enrollment was gathered from local administrators.

\section{Study Design}


This study compares survey results from two cross-sectional samples, rather than a longitudinal design; that is, we do not track the same individuals over time but instead collect information from the population of interest before and after the Promise intervention. This approach reflects logistical and financial considerations; funding and personnel allowed collection of cross-sectional but not longitudinal data. Analytically, the repeated cross-sectional approach we use sets a higher bar for finding a relationship between the Promise program and parental educational expectations. Because program exposure is measured with more error than in longitudinal analyses, our estimates will be underestimated. For example, the post-Promise survey includes families who moved into the district after the program was implemented and were not fully exposed to the elements of the program. However, as in many evaluations of public health interventions (e.g., Marston et al. 2005; Shults and Beck 2012), we seek to include potential spillovers in our estimation. That is, families who did not fully participate in the program (e.g., did not opt to open a CSA) or families who enrolled their children in the school after implementation may still receive benefits. For example, parents or children may hear more about the benefits of college or how to prepare for college costs from other families at the school. Public health studies often use a similar repeated cross-sectional design to estimate the relationship between an intervention and behaviors or health measures (e.g., Marston et al. 2005; Shults and Beck 2012; Giganti et al. 2010). In some cases, economists also use repeated crosssectional analyses to examine social or spillover effects. For example, Moretti (2004) found similar estimates of the social returns to higher education using longitudinal and cross-sectional data.

Because we use repeated cross-sectional data, the key assumption for this analysis is that the survey respondents before and after The Promise intervention are similar. To test this, we 
conduct two-tailed t-tests on a host of measures that may be related to parental educational expectations among the respondents before and after the intervention. These include parental education, income, marital status, family structure, parental age, child gender, child race, and grade level. Only one difference is statistically significant $(\mathrm{p}<0.05)$ : grade level of the student. Parents are surveyed in the spring before the intervention and the fall after the intervention. The students who received the intervention have moved up a grade in school. Overall, then, these comparisons suggest survey respondents before and after The Promise intervention are similar on multiple measures that may be related to parental educational expectations.

Sample. Parents of children in kindergarten, $1^{\text {st }}$ grade, $2^{\text {nd }}$ grade, and $3^{\text {rd }}$ grade who attended schools in Wabash, LaGrange, Noble, and Whitley counties were surveyed for this study in the spring. Families of $3^{\text {rd }}$ graders surveyed in the spring (pre) were not surveyed in the fall (post) because those students had been promoted to $4^{\text {th }}$ grade. The final sample consisted of 3,339 families. However, 3,060 families responded to all of the questions used in this analysis, and our sample is limited to these families with complete information (see Table 1).

\section{Variables of Interest}

529 account status. Has a 529 is an indicator for those who have a 529 account (coded 1) versus all others (coded 0; i.e., those with no account and those who have savings for college not in a 529). Parents were asked, “Are you currently saving or investing for any of your child’s college education?” If they answered yes, they were asked, "Which of the following have you used to save money for your child’s education?” Options were: savings or money market accounts or CDs; retirement savings such as 401(k), IRA; Coverdell Education Savings Account; Uniform Gift to Minors Act/ Uniform Transfers; prepaid or guaranteed college savings; 529 
college savings plan; stocks or bonds; mutual fund; other. Having a 529 account is of particular interest to this study because the advertising campaign worked to increase parental knowledge of and access to 529 accounts for their children. More specifically, CollegeChoice 529 accounts are part of The Promise Program.

Promise plus. The Promise Plus variable is the indicator for the post-survey $(0=$ presurvey; 1 = post-survey). Over the summer of 2013, Promise Indiana (or Promise, for short) launched a marketing campaign in Wabash County. Further, initial enrollment in the Promise occurred during school registrations July 29 through August 2, 2013 in Wabash County. The marketing campaign, school activities related to college and career preparation, information about engaging champions, trip to a university, and the opportunity to enroll into the Promise is what is referred to in this study as Promise Plus. ${ }^{2}$ In fall 2013 the post survey was administered in Wabash County. Other counties followed a similar timeline, but in 2014 instead of 2013.

Promise Plus is an indicator for living in a county where the program was rolled out. Because the advertising campaign and enrollment efforts were extensive, we assume at least some exposure to the Promise message. This does not mean that an individual was actually enrolled in the program, only that the parent was given the opportunity to enroll. Thus, estimates of the relationship between Promise Plus and parental expectations are similar to an intent-totreat or reduced-form estimate. The estimate does not rely on individual selection into a 529 account and therefore remains unbiased to heterogeneous responses (Freedman, 2006) to the Promise program. For example, parents who would not open a 529 account regardless of being offered incentives or opportunities to do so may have other disadvantages - such as poverty, family strain, or financial insecurity - that would also dampen educational expectations for their

\footnotetext{
${ }^{2}$ We call it The Promise Plus because Promise Indiana includes components that have not traditionally been included in CSA programs. The typical CSA program usually only consists of an account, match, and incentives.
} 
children. Those who open a 529 regardless of exposure to the Promise campaign may similarly maintain higher educational expectations. These differences would bias an instrumental variable (or treatment-on-the-treated) estimate of the effect of a CSA program. An intent-to-treat estimate (used here) is robust to these responses (Freedman, 2006) and also allows the Promise program to influence educational expectations through mechanisms other than opening a 529 account.

Has a 529 x Promise Plus. We create an interaction between having a 529 and living in a county where Promise Indiana was rolled out. This is an imperfect proxy for actual enrollment in the CSA component of Promise Indiana. We say it is imperfect, as are all proxies, because having a 529 and the advertising campaign are not the only components of the Promise; additionally, some parents already had a 529 account before exposure to Promise Indiana. Despite the limitation of this proxy, it captures two key components of the Promise Indiana model.

Expects any college. The primary outcome of interest - parent education expectations is measured in terms of whether parents expect their child to attend any college. Parents who expect their child to attend 2-Year College, 4-Year College, or Advanced Degree are coded as expecting their child to attend any college. Parents who expect their child to attend only through Middle School, High School, Military Service, or Vocational or Certificate Program are coded as expecting their child to not attend college.

\section{Covariates}

Parental education level. Parents were asked, "What is the highest level of formal schooling attained in your household?” Options were: some high school; high school 
graduate/GED; professional certification; some college, associate's degree, bachelor's degree, or masters or professional degree. Using this information, we created two measures of parental education: 1) at least one parent had a bachelor degree or higher, compared to all other education levels; and 2) at least one parent had any college education, including those with some college, an associate's degree, a bachelor's degree, or a masters or professional degree compared to those with less education.

Family income level. Parent report of annual household income was recoded from 3 response options (less than $\$ 50,000$; $\$ 50,000$ - $\$ 100,000$; or more than $\$ 100,000$ ) to a dichotomous variable (less than $\$ 50,000$ and $\$ 50,000$ or more). We chose the cut point of less than $\$ 50,000$ because these families may have lower expectations for their children and face more financial burdens than those with higher incomes.

Family structure. Family structure is measured as a single variable with the response options: child's parents are married, single parent, grandparents, and other. Based on these responses, we create an indicator for whether or not the child's parents are married.

Parental Age. Parent report of age was recoded from a three-level variable (18 - 34; 35 54; 55 and older) into a dichotomous variable, including parents ages 18 - 34 compared to all others. We chose the cut point of ages 18 - 34 because younger parents may struggle more than older parents, who tend to enjoy greater stability, may be more educated, and may hold higher expectations for their children.

Child's gender. Gender was coded with females as the reference group (i.e. the omitted category in regressions).

Child's race. The race/ethnicity variable was coded as white and nonwhite with nonwhites as the reference group. Nonwhites were combined into a single group because there 
were small numbers of nonwhites in the sample (white, 86 percent or 2,663 children;

Hispanic/Latino, nine percent or 295 children; African American, less than one percent or 31

children; Asian or Pacific Islander, less than one percent or 20 children; other, one percent or 51 children).

Child's grade level. Parents were asked, "Which of the following grade levels is your child currently attending?” Parents could choose from: kindergarten; $1^{\text {st }}$ grade; $2^{\text {nd }}$ grade; and $3^{\text {rd }}$ grade. Kindergarten is the reference group.

County. Families from this study come from one of four counties in Indiana: Wabash; LaGrange; Noble; and Whitley Counties. Wabash is the reference group.

\section{Analysis Plan}

First, we present descriptive information for the entire sample (pre- and post-survey) as well as separately for those who expect their child to attend some college, are low- or highincome (i.e. above or below $\$ 50,000$ ), and have no college or some college education. While descriptive information is informative, any association between educational expectations and Promise Plus or its interaction with having a 529 could reflect differences in race, education, income, or other characteristics. To account for these observed measures, we use logistic regression models to predict parental educational expectations using an indicator for Promise plus (post-survey) while accounting for variation in parental and child characteristics. Specifically, combining the pre- and post-survey data, we predict whether a parent expects his/her child to attend some college, controlling for parental education, marital status, and age, family income, and child gender, race, and grade level. We also include county-level fixed effects to adjust for potential county-level differences in parental expectations (StataCorp, 2013). 
Because there are multiple households in each county, we adjust standard errors for county-level clustering with the robust cluster command (StataCorp, 2013). Sensitivity analyses adjusting for school-level clustering yield slightly lower standard errors but do not change the significance of any of our independent variables of interest.

Our main coefficient of interest is Promise plus, the indicator for respondents to the survey collected after the program was implemented. The coefficient for Promise plus estimates whether parental educational expectations differed significantly after the program was implemented.

Model 1. The base model, Model 1, estimates the relationship between having a 529 account and parental educational expectations, controlling for parental education level, family income level, parental marital status, parental age, child’s gender, child’s race, child’s grade level, and indicators for each county. This model estimates the strength of the association between having a 529 account and parental expectations in the whole sample.

Model 2. Subsequently, to determine whether exposure to The Promise program has an independent relationship with parental expectations, we estimate two additional logistic regressions (Models 2 \& 3). Model two drops the indicator for having a 529 account and replaces it with The Promise Plus variable. This model provides a reduced-form estimate of the relationship between Promise Plus and parental educational expectations.

Model 3. Model 3 tests the interaction between having a 529 account and Promise Plus. The model includes the indicators for 'has a 529 account' and Promise Plus, as well as the interaction between the two variables.

CSA programs are often aimed at low-income families or those with parents who have not attained a college degree, in part because these families may experience a greater benefit 
from CSAs and in part because CSAs are designed to affect disparities in educational outcomes. In order to detect if there are differences by income (low-income = below $\$ 50,000$; high-income $=\$ 50,000$ or above) or parental education level (no college $=$ no college attendance; some college = having taken some classes at a 2-year college or higher), we fit the above three models to subsamples limited to: low-income families; high-income families; parents with no college; and parents who have some college education or more.

\section{Sensitivity Analysis}

In sensitivity analyses, we further excluded parents of children in grades that were not included in the pre-survey or post-survey. Specifically, we excluded parents of third graders in the spring survey because their students were in fourth grade in the spring and not surveyed. We excluded kindergarteners in the fall survey because they were not enrolled in school in the spring and not surveyed. This limited sample is not used in our main analysis because the key assumption for this analysis is that the samples are similar before and after The Promise Plus. Results are similar - or, if anything, suggest a stronger relationship between Promise Plus and parental expectations - to those using the full sample. However, the results based on the full sample are preferred because they offer more conservative estimates.

\section{Results}

This section reports descriptive statistics from the College and Career Planning Survey sample (see Table 2). The aggregate statistics in Table 2 are column percentages; the remaining disaggregated columns are row percentages.

Table 2. Descriptive Statistics from the College and Career Planning Survey Sample, Reported as Percentages 


\begin{tabular}{|c|c|c|c|c|c|c|}
\hline & All & $\begin{array}{l}\text { Expect Any } \\
\text { College }\end{array}$ & $\begin{array}{l}\text { Low- } \\
\text { Income }\end{array}$ & $\begin{array}{l}\text { High- } \\
\text { Income }\end{array}$ & $\begin{array}{c}\text { No } \\
\text { College }\end{array}$ & $\begin{array}{c}\text { Some } \\
\text { College }\end{array}$ \\
\hline Expect Any College & 81 & -- & 80 & 82 & 58 & 95 \\
\hline Has 529 & 22 & 27 & 13 & 31 & 8 & 31 \\
\hline Has 529 pre-Promise & 9 & 11 & 3 & 16 & 1 & 14 \\
\hline Has 529 post-Promise & 34 & 40 & 22 & 45 & 14 & 46 \\
\hline Promise Plus & 53 & 54 & 53 & 53 & 53 & 53 \\
\hline Has 529 x Promise Plus & 18 & 22 & 12 & 24 & 7 & 25 \\
\hline Parent Has a BA & 28 & 34 & 10 & 44 & -- & -- \\
\hline Income $>\$ 50,000$ & 52 & 53 & -- & -- & 37 & 61 \\
\hline Parents Married & 72 & 73 & 53 & 89 & 63 & 77 \\
\hline Parent Age 18-34 & 52 & 51 & 61 & 43 & 58 & 48 \\
\hline Child Male & 51 & 50 & 51 & 52 & 49 & 52 \\
\hline Child White & 87 & 86 & 81 & 93 & 81 & 91 \\
\hline \multicolumn{7}{|l|}{ Child Grade Level } \\
\hline Kindergarten & 36 & 35 & 37 & 35 & 37 & 35 \\
\hline 1st Grade & 26 & 27 & 25 & 27 & 24 & 27 \\
\hline 2nd Grade & 25 & 24 & 24 & 25 & 25 & 24 \\
\hline 3rd Grade & 13 & 14 & 13 & 13 & 14 & 13 \\
\hline \multicolumn{7}{|l|}{ County } \\
\hline Wabash County & 22 & 26 & 24 & 21 & 15 & 27 \\
\hline LaGrange County & 26 & 20 & 23 & 28 & 38 & 18 \\
\hline Noble County & 41 & 42 & 42 & 39 & 40 & 41 \\
\hline Whitley County & 11 & 12 & 10 & 12 & 7 & 14 \\
\hline Observations (N) & 3,060 & 2,483 & 1,467 & 1,593 & 1,167 & 1,893 \\
\hline
\end{tabular}

Note. The interaction between having a 529 account (Has 529) and exposure to the advertising campaign combined with the opportunity to enroll in a 529 account (Promise Plus) is a proxy for participation in The Promise Program.

Among all parents sampled for this study, 81 percent expect their child to attend college (i.e., 2-year college, 4-year college, or advanced degree), 22 percent have a 529 account (9 percent before Promise and 34 percent after Promise), 18 percent experienced the Promise (i.e., actually had a 529 account and were exposed to the advertising campaign combined with the opportunity to enroll in a 529 account ), 52 percent are high-income, 28 percent have a bachelor degree, and 87 percent are white. 
With regard to the subgroups described here, 27 percent of parents who expect their child to attend college have a 529 account, while 13 percent of low-income parents, 31 percent of high-income, 8 percent of parents with no college, and 31 percent of parents with some college have a 529 account. In the full sample and across all subgroups in Table 1, the proportion holding a 529 account is multiple times higher after the Promise program than before it.

Interestingly, similar percentages of low-income (80 percent) and high-income (82 percent) parents surveyed expect their child to attend college. However, only 58 percent of parents with no college expect their child to attend college, compared to 95 percent of parents with some college education. Consistent with national trends, a high percentage of parents who are low-income (47 percent) and parents with no college (37 percent) are not married.

\section{Logistic Regression Results}

Expect any college: Aggregate sample. The variable of interest in Table 3, Model 1 is having a 529 account. Having a 529 account to help pay for their child's education is a positive significant predictor of parents expecting their child to attend any college (i.e., 2-Year College, 4-Year College, or Advanced Degree). The odds of parents expecting their child to attend any college if they have opened a 529 account is approximately four and half times higher than for parents who have not opened a 529 account (odds ratio $=4.497, \mathrm{p}<.05$ ). In Model 2 the variable of interest is The Promise Plus. The odds of parents expecting their child to attend any college is about 59 percent higher after Promise Plus than prior to Promise Plus (odds ratio $=1.594, \mathrm{p}<$ .05). The interaction between having a 529 and Promise Plus was tested in Model 3. Parents who fully experience The Promise are approximately three times more likely to expect their child to attend any college than if they do not experience The Promise (odds ratio $=3.315, \mathrm{p}<.05$ ). The 
coefficients for having a 529 account and Promise Plus in Model 3 are not significantly different from zero.

If parents have a bachelor degree and are age 18-34, they have higher odds of expecting their child to attend any college. The odds of parents with a bachelor degree expecting their child to attend any college are about fifteen times higher than the odds of parents without a bachelor degree $($ odds ratio $=14.815, \mathrm{p}<.01)$. Younger parents $(18-34)$ have nearly 20 percent higher odds of expecting their child to attend any college when compared to older parents (odds ratio $=$ 1.199, $\mathrm{p}<.01)$

Some controls have a negative relationship with the odds of parents expecting their children to attend any college (parents with a white child and parents with a child living in LaGrange, Noble, and Whitley when compared to Wabash County). The odds of parents of white children expecting their child to attend any college are 57 percent less than parents of non-white children (odds ratio $=0.431, \mathrm{p}<.01$ ). Parents of children who live in LaGrange (86 percent), Noble (49 percent), and Whitley (56 percent) counties are less likely to expect their child to attend any college than parents of children who live in Wabash County (odds ratios $=0.144$, 0.517, and 0.445 respectively, $\mathrm{p}<.01$ for all three counties). Interpreted differently, parents in LaGrange County are nearly 7 times less likely to expect their children to attend college than parents in Wabash County. In Noble and Whitley counties, parents are approximately two times less likely to expect their children to attend college than those in Wabash County. To avoid redundancy, we only write out results for control variables in Model 1 of each Table. In nearly all cases, the coefficients for the control variables are similar across all three models. Table 3. Parental Expectations for Child Education - Aggregate Sample

\begin{tabular}{ccc|cc|cc}
\hline & \multicolumn{2}{c|}{ Model $1(N=3,060)$} & \multicolumn{2}{c|}{ Model $2(N=3,060)$} & \multicolumn{2}{c}{ Model 3 $(N=3,060)$} \\
\hline Variable Names & $B$ & Robust OR & B & Robust OR & B & Robust OR \\
& & $S E$ & & $S E$ & $S E$ \\
\hline
\end{tabular}




\begin{tabular}{|c|c|c|c|c|c|c|c|c|c|}
\hline Has 529 & 1.503* & 0.665 & 4.497 & --- & --- & --- & 0.441 & 0.383 & --- \\
\hline Promise Plus & --- & --- & --- & $0.466^{*}$ & 0.203 & 1.594 & 0.219 & 0.209 & --- \\
\hline $\begin{array}{l}\text { Has } 529 \text { x Promise } \\
\text { Plus }\end{array}$ & --- & --- & --- & --- & --- & --- & $1.199 *$ & 0.584 & 3.315 \\
\hline Parent has a BA or & & & & & & & & & \\
\hline $\begin{array}{l}\text { Higher } \\
\text { Income } \$ 50,000 \text { or }\end{array}$ & $2.696 * *$ & 0.684 & 14.815 & $3.004^{* *}$ & 0.827 & 20.167 & $2.767 * *$ & 0.707 & 15.913 \\
\hline more & -0.219 & 0.456 & & -0.178 & 0.462 & --- & -0.209 & 0.465 & --- \\
\hline Parents Married & 0.204 & 0.336 & & 0.244 & 0.341 & --- & 0.215 & 0.336 & --- \\
\hline Parent Age 18-34 & $0.181 * *$ & 0.067 & 1.199 & $0.134 *$ & 0.058 & 1.144 & $0.172 *$ & 0.067 & 1.187 \\
\hline Child Male & -0.388 & 0.220 & & -0.380 & 0.201 & --- & -0.388 & 0.214 & --- \\
\hline Child White & $-0.841 * *$ & 0.163 & 0.431 & $-0.811 * *$ & 0.179 & 0.444 & $-0.849 * *$ & 0.189 & 0.428 \\
\hline Child Grade Level & 0.096 & 0.090 & & 0.062 & 0.078 & --- & 0.067 & 0.098 & --- \\
\hline LaGrange County $^{\mathrm{a}}$ & $-1.936 * *$ & 0.148 & 0.144 & $-2.131 * *$ & 0.143 & 0.119 & $-1.988 * *$ & 0.168 & 0.137 \\
\hline Noble County ${ }^{\mathrm{a}}$ & $-0.659 * *$ & 0.133 & 0.517 & $-0.766^{* *}$ & 0.084 & 0.465 & $-0.629 * *$ & 0.119 & 0.533 \\
\hline Whitley County ${ }^{\mathrm{a}}$ & $-0.809 * *$ & 0.135 & 0.445 & $-0.842 * *$ & 0.115 & 0.431 & $-0.779 * *$ & 0.134 & 0.459 \\
\hline Constant & $2.641^{* *}$ & 0.159 & --- & $2.647 * *$ & 0.198 & --- & $2.575 * *$ & 0.157 & -- \\
\hline
\end{tabular}

Note. Robust standard errors adjusted for county-level clustering in parentheses. BA = Bachelor Degree. Child grade level is ordinal with $0=$ kindergarten, $1=$ first grade, $2=$ second grade and so forth.

${ }^{a}$ Wabash County was the reference group

** $\mathrm{p}<0.01, * \mathrm{p}<0.05$

Expect any college: Low-income sample. Results from Table 4 are restricted to low-

income parents only. Low-income is defined as having self-reported income below $\$ 50,000$. To

preserve space, only results from the variables of interest are written out in the text for the

disaggregated samples (Tables $4-7$ ).

Among this low-income sample, the odds of parents expecting their child to attend any college is nearly two and half times higher if they have a 529 account than if they do not (odds ratio $=2.434, \mathrm{p}<.05)$. Promise Plus and its interaction with having a 529 are not statistically significant in Models 2 and 3 (see Table 4).

Table 4. Predicted Low-Income Parental Expectations for Child Education - Any College

\begin{tabular}{|c|c|c|c|c|c|c|c|c|c|}
\hline & \multicolumn{3}{|c|}{ Model $1(n=1,467)$} & \multicolumn{3}{|c|}{ Model $2(n=1,467)$} & \multicolumn{3}{|c|}{ Model $3(n=1,467)$} \\
\hline Variable Names & $B$ & $\begin{array}{c}\text { Robust } \\
\text { SE }\end{array}$ & OR & $B$ & $\begin{array}{c}\text { Robust } \\
\text { SE }\end{array}$ & OR & $B$ & $\begin{array}{c}\text { Robust } \\
\text { SE }\end{array}$ & OR \\
\hline Has 529 & $0.890 *$ & 0.369 & 2.434 & --- & --- & --- & -0.110 & 0.596 & --- \\
\hline Promise Plus & --- & --- & --- & 0.159 & 0.194 & --- & 0.006 & 0.212 & --- \\
\hline
\end{tabular}




\begin{tabular}{|c|c|c|c|c|c|c|c|c|c|}
\hline $\begin{array}{l}\text { Has } 529 \text { x Promise } \\
\text { Plus }\end{array}$ & --- & --- & --- & --- & --- & --- & 1.176 & 0.746 & --- \\
\hline \multicolumn{10}{|l|}{ Parent Has a BA or } \\
\hline Higher & $2.152 *$ & 0.887 & 8.599 & $2.193 *$ & 0.891 & 8.966 & $2.177 *$ & 0.910 & 8.819 \\
\hline Parents Married & 0.025 & 0.368 & --- & 0.047 & 0.371 & --- & 0.026 & 0.370 & --- \\
\hline Parent Age 18-34 & $0.242 * *$ & .086 & --- & $0.237 * *$ & 0.088 & 1.268 & $0.234 * *$ & 0.090 & 1.263 \\
\hline Child Male & -0.473 & .302 & --- & -0.457 & 0.282 & --- & -0.466 & 0.292 & \\
\hline Child White & $-0.858 * *$ & 0.199 & 0.424 & $-0.838 * *$ & 0.210 & 0.432 & $-0.856 * *$ & 0.199 & 0.425 \\
\hline Child Grade Level & $0.110^{* *}$ & 0.041 & 1.117 & $0.115^{* *}$ & 0.042 & 1.121 & $0.104^{* *}$ & 0.039 & 1.110 \\
\hline LaGrange County ${ }^{a}$ & $-1.336 * *$ & 0.094 & 0.263 & $-1.434 * *$ & 0.095 & 0.238 & $-1.332 * *$ & 0.114 & 0.264 \\
\hline Noble County ${ }^{\mathrm{a}}$ & $-0.657 * *$ & 0.075 & 0.519 & $-0.755^{* *}$ & 0.026 & 0.470 & $-0.637 * *$ & 0.046 & 0.529 \\
\hline Whitley County ${ }^{\mathrm{a}}$ & $-1.158 * *$ & 0.083 & 0.314 & $-1.207 * *$ & 0.120 & 0.299 & $-1.127 * *$ & 0.122 & 0.324 \\
\hline Constant & $2.634 * *$ & 0.257 & --- & $2.670 * *$ & 0.235 & --- & $2.621 * *$ & 0.202 & --- \\
\hline
\end{tabular}

Note. Robust standard errors adjusted for county-level clustering in parentheses. BA = Bachelor Degree. Child grade level is ordinal with $0=$ kindergarten, $1=$ first grade, $2=$ second grade and so forth.

${ }^{a}$ Wabash County was the reference group

** $\mathrm{p}<0.01, * \mathrm{p}<0.05$

Expect any college: High-income sample. Table 5 results are restricted to high-income parents only. High-income is defined as having self-reported income of \$50,000 or more. Among this sample, the odds of high-income parents in this survey expecting their child to attend any college is about eight times higher if they have a 529 account than if they do not (odds ratio = 8.896, $\mathrm{p}<.1$ ). In Model 2, the odds of parents expecting their child to attend any college after Promise Plus is about two and half times more than prior to Promise Plus (odds ratio $=2.662$, $\mathrm{p}$ $<$.01). The interaction between having a 529 and Promise Plus is not significant in Model 3 (see Table 5). However, the coefficient for Promise Plus remains significant in Model 3, suggesting that exposure is associated with higher educational expectations even when holding constant whether parents have a 529 account.

Table 5. Predicted High-Income Parental Expectations for Child Education - Any College

\begin{tabular}{|c|c|c|c|c|c|c|c|c|c|}
\hline & \multicolumn{3}{|c|}{ Model $1(n=1,593)$} & \multicolumn{3}{|c|}{ Model $2(n=1,593)$} & \multicolumn{3}{|c|}{ Model $3(n=1,593)$} \\
\hline Variable Names & $B$ & $\begin{array}{c}\text { Robust } \\
\text { SE }\end{array}$ & OR & $B$ & $\begin{array}{c}\text { Robust } \\
\text { SE }\end{array}$ & $O R$ & $B$ & $\begin{array}{c}\text { Robust } \\
\text { SE }\end{array}$ & $O R$ \\
\hline Has 5 & 2.186 & 1.135 & 8.896 & --- & --- & --- & 0.741 & 0.755 & -- \\
\hline Promise Plus & --- & --- & --- & $0.979 * *$ & 0.308 & 2.662 & $0.617^{*}$ & 0.271 & 1.853 \\
\hline
\end{tabular}




\begin{tabular}{|c|c|c|c|c|c|c|c|c|c|}
\hline \multicolumn{3}{|l|}{ Has 529 x Promise } & --- & --- & --- & --- & 1.556 & 1.406 & --- \\
\hline Plus & --- & --- & & & & & & & \\
\hline \multicolumn{10}{|l|}{ Parent Has a BA or } \\
\hline Higher & $2.808 * *$ & 0.651 & 16.584 & $3.334 * *$ & 0.873 & 28.056 & $3.003 * *$ & 0.757 & 20.143 \\
\hline Parents Married & $0.505^{*}$ & 0.204 & 1.657 & $0.524^{*}$ & 0.246 & 1.688 & $0.529 *$ & 0.207 & 1.697 \\
\hline Parent Age 18-34 & $0.282 *$ & 0.127 & 1.326 & 0.153 & 0.090 & & $0.256^{*}$ & 0.125 & 1.292 \\
\hline \multirow[t]{2}{*}{ Child Male } & & 0.061 & & - & & & & & \\
\hline & $-0.147^{*}$ & & 0.863 & $0.202^{* *}$ & 0.051 & 0.817 & $-0.181 * *$ & 0.051 & 0.834 \\
\hline Child White & $-0.481^{*}$ & 0.211 & 0.618 & $-0.317^{*}$ & 0.138 & 0.728 & -0.443 & 0.252 & --- \\
\hline Child Grade Level & 0.144 & 0.221 & --- & 0.040 & 0.195 & --- & 0.071 & 0.235 & --- \\
\hline \multirow[t]{2}{*}{ LaGrange County } & - & 0.005 & & - & & & & & \\
\hline & $2.796 * *$ & & 0.061 & $3.163 * *$ & 0.112 & 0.042 & $-3.015 * *$ & 0.142 & 0.049 \\
\hline \multirow[t]{2}{*}{ Noble County ${ }^{\mathrm{a}}$} & - & 0.138 & & - & & & & & \\
\hline & $0.880 * *$ & & 0.415 & $0.937 * *$ & 0.091 & 0.392 & $-0.827 * *$ & 0.122 & 0.438 \\
\hline Whitley County ${ }^{\mathrm{a}}$ & 0.305 & 0.306 & --- & 0.196 & 0.264 & --- & 0.255 & 0.315 & --- \\
\hline Constant & $1.982 * *$ & 0.233 & --- & $1.932 * *$ & 0.159 & --- & $1.837 * *$ & 0.178 & --- \\
\hline
\end{tabular}

Note. Robust standard errors adjusted for county-level clustering in parentheses. BA = Bachelor

Degree. Child grade level is ordinal with $0=$ kindergarten, $1=$ first grade, $2=$ second grade and so forth.

${ }^{\mathrm{a}}$ Wabash County was the reference group

${ }^{\mathrm{b}}$ Has 529 approaches significance in Model 1, $\mathrm{p}=.054$.

** $\mathrm{p}<0.01,{ }^{*} \mathrm{p}<0.05$

Expect any college: No college sample. Table 6 results are restricted to parents with no college education. The odds of parents with no college expecting their child to attend any college is about three times higher if they have a 529 account than if they do not (odds ratio $=3.378$, $\mathrm{p}<$ .1). In Model 2, the odds of parents with no college expecting their child to attend any college after Promise Plus are about 68 percent higher than prior to Promise Plus (odds ratio $=1.678, \mathrm{p}$ $<$.05). The interaction between having a 529 and Promise Plus is significant in Model 3. Parents with no college who are exposed to the Promise program and have a 529 account are approximately thirteen times more likely to expect their child to attend any college than if they do not (odds ratio $=13.083, \mathrm{p}<.01)$ (see Table 6).

Table 6. Predicted Expectations of Parents with No College for Child Education - Any College

\begin{tabular}{clc|ccc|cc}
\hline & \multicolumn{2}{l|}{ Model 1 $(n=1,167)$} & \multicolumn{2}{|c}{ Model $2(n=1,167)$} & \multicolumn{2}{c}{ Model 3 $(n=1,167)$} \\
\hline Variable Names & $B$ & $\begin{array}{c}\text { Robust } \\
\text { SE }\end{array}$ & OR & Robust OR & $B$ & Robust & OR \\
& & SE & SE & \\
\hline
\end{tabular}




\begin{tabular}{lccc|ccc|ccc}
\hline Has 529b & 1.217 & 0.723 & 3.378 & --- & --- & --- & $-1.055^{* *}$ & 0.400 & -- \\
Promise Plus & --- & --- & --- & $0.517^{*}$ & 0.240 & 1.678 & 0.349 & 0.267 & 1.418 \\
$\quad$ Has 529 x Promise & & & --- & -- & --- & --- & $2.571^{* *}$ & 0.857 & 13.083 \\
$\quad$ Plus & --- & --- & & & & & & & \\
$\quad$ Income \$50,000 or & & & & & & & & & \\
$\quad$ more & -0.640 & 0.367 & --- & -0.633 & 0.382 & --- & -0.622 & 0.373 & --- \\
Parents Married & -0.018 & 0.367 & --- & 0.005 & 0.353 & --- & -0.002 & 0.362 & --- \\
Parent Age 18-34 & $0.348^{* *}$ & 0.046 & 1.416 & $0.330^{* *}$ & 0.021 & 1.391 & $0.359^{* *}$ & 0.041 & 1.432 \\
Child Male & -0.359 & 0.280 & --- & -0.351 & 0.255 & --- & -0.342 & 0.258 & -- \\
Child White & $-1.296^{* *}$ & 0.205 & 0.274 & $-1.299^{* *}$ & 0.221 & 0.273 & $1.305^{* *}$ & 0.238 & 0.271 \\
Child Grade Level $^{2}$ & 0.170 & 0.098 & --- & 0.126 & 0.098 & --- & 0.132 & 0.109 & --- \\
LaGrange County $^{\mathrm{a}}$ & $-1.776^{* *}$ & 0.156 & 0.169 & $-1.958^{* *}$ & 0.145 & 0.141 & $-1.833^{* *}$ & 0.165 & 0.160 \\
Noble County $^{\mathrm{a}}$ & $-0.706^{* *}$ & 0.108 & 0.493 & $-0.745^{* *}$ & 0.075 & 0.475 & $-0.633^{* *}$ & 0.096 & 0.531 \\
Whitley County $^{\mathrm{a}}$ & $-1.496^{* *}$ & 0.152 & 0.224 & $-1.476^{* *}$ & 0.113 & 0.229 & $-1.322^{* *}$ & 0.141 & 0.267 \\
Constant $^{\quad}$ & $2.476^{* *}$ & 0.245 & --- & $2.418^{* *}$ & 0.287 & --- & $2.303^{* *}$ & 0.241 & --- \\
\hline
\end{tabular}

Note. Robust standard error s adjusted for county-level clustering in parentheses. BA = Bachelor Degree. Child grade level is ordinal with $0=$ kindergarten, 1 = first grade, $2=$ second grade and so forth.

${ }^{a}$ Wabash County was the reference group

${ }^{b}$ Has 529 approaches significance $\mathrm{p}=0.092$.

** $\mathrm{p}<0.01,{ }^{*} \mathrm{p}<0.05$

Expect any college: Some college sample. Table 7 results are restricted to parents with some college education. The odds of parents with no college expecting their child to attend any college is about three times higher if they have a 529 account than if they do not (odds ratio = 2.849, $\mathrm{p}<.01$ ). In Model 2, the odds of parents with no college expecting their child to attend any college are not significantly different before and after Promise Plus. Similarly, in Model 3 the coefficient for the interaction between having a 529 and Promise Plus is not significant.

Table 7. Predicted Expectations of Parents with Some College for Child Education - Any College

\begin{tabular}{|c|c|c|c|c|c|c|c|c|c|}
\hline & \multicolumn{3}{|c|}{ Model $1(n=1,893)$} & \multicolumn{3}{|c|}{ Model $2(n=1,893)$} & \multicolumn{3}{|c|}{ Model $3(n=1,893)$} \\
\hline Variable Names & B & $\begin{array}{l}\text { Robust } \\
\text { SE }\end{array}$ & OR & $B$ & $\begin{array}{c}\text { Robus } \\
\mathrm{t} \\
S E\end{array}$ & OR & $B$ & $\begin{array}{c}\text { Robust } \\
\text { SE }\end{array}$ & $O R$ \\
\hline Has 529 & $1.047^{* *}$ & 0.400 & 2.849 & --- & --- & --- & $1.477^{*}$ & 0.707 & 4.382 \\
\hline Promise Plus & --- & --- & --- & 0.097 & 0.267 & --- & -0.107 & 0.228 & --- \\
\hline $\begin{array}{l}\text { Has } 529 \text { x Promise } \\
\text { Plus }\end{array}$ & --- & --- & -- & --- & --- & --- & -0.449 & 0.698 & --- \\
\hline $\begin{array}{l}\text { Income } \$ 50,000 \text { or } \\
\text { more }\end{array}$ & 0.539 & 0.291 & --- & $0.661 *$ & 0.261 & 1.937 & 0.531 & 0.294 & 1.701 \\
\hline
\end{tabular}




\begin{tabular}{lccc|ccc|ccc} 
Parents Married & $0.550^{* *}$ & 0.162 & 1.733 & $0.615^{* *}$ & 0.171 & 1.849 & $0.547 * *$ & 0.156 & 1.727 \\
Parent Age 18-34 & -0.146 & 0.137 & --- & -0.199 & 0.108 & --- & -0.135 & 0.119 & 0.874 \\
Child Male & $-0.889 * *$ & 0.146 & 0.411 & $-0.887^{* *}$ & 0.122 & 0.412 & $-0.889 * *$ & 0.144 & 0.411 \\
Child White & -0.012 & 0.235 & --- & 0.037 & 0.257 & --- & -0.018 & 0.248 & 0.982 \\
Child Grade Level $^{\text {L }}$ & -0.149 & 0.100 & --- & -0.146 & 0.133 & --- & -0.132 & 0.126 & 0.876 \\
LaGrange County $^{\mathrm{a}}$ & $-1.186^{* *}$ & 0.042 & 0.305 & $-1.267 * *$ & 0.033 & 0.282 & $-1.167 * *$ & 0.052 & 0.311 \\
Noble County $^{\mathrm{a}}$ & $-0.689^{* *}$ & 0.055 & 0.502 & $-0.858^{* *}$ & 0.020 & 0.424 & $-0.701^{* *}$ & 0.056 & 0.496 \\
Whitley County $^{\mathrm{a}}$ & 0.177 & 0.142 & --- & 0.086 & 0.172 & --- & 0.195 & 0.168 & --- \\
Constant & $3.533^{* *}$ & 0.070 & --- & $3.666^{* *}$ & 0.142 & --- & $3.565^{* *}$ & 0.152 & --- \\
\hline
\end{tabular}

Note. Robust standard errors adjusted for county-level clustering in parentheses. BA = Bachelor Degree. Child grade level is ordinal with $0=$ kindergarten, $1=$ first grade, $2=$ second grade and so forth.

${ }^{a}$ Wabash County was the reference group

** $\mathrm{p}<0.01, * \mathrm{p}<0.05$

Overall, our results suggest that parents are more likely to expect their elementary-school children to attend college after implementation of the Promise and if they have a 529 account.

Moreover, educational expectations after the Promise program are even higher among those who have a 529 account. These results, however, differ by parental income and education. For example, Promise Plus is associated with higher educational expectations among high-income families and among parents without any college education.

\section{Discussion}

Overall, the results suggest that parents are more likely to expect their elementary-school children to attend college if they have a 529 account. It might be argued that it is not surprising that having a 529 account is correlated with more positive parental expectations because parents typically only invest in a 529 account if they expect their child to benefit from the account by attending college. However, results from this study shed additional light on these dynamics and underscore the extent to which parental characteristics and the parameters of the intervention may influence the expectations that parents hold and the actions they take to live up to them. The evidence suggests that Promise Plus is correlated most strongly with parents' educational 
expectations when combined with having an account. Specifically, parents who were both exposed to the program and have a 529 account are over three times more likely to expect their child to attend college than others; this difference increases to 13 times more likely when limited to parents with no college education.

Here, we consider each of these findings in turn and in juxtaposition with the existing literature base. First, this study found that merely having a Children's Savings Account is associated with higher expectations among low-income families. This is consistent with previous research, particularly from the SEED for Oklahoma Kids randomized control trial. There, while analysis found that parents who have a 529 account as part of SEED OK generally have higher expectations for their children than parents in the control group, these effects were strongest for the poorest families (Kim, Sherraden, Huang, \& Clancy, 2015). These low-income parents, whose expectations of their children's college educations may be more vulnerable to erosion as parents confront the realities of college financing and attempt to navigate unfamiliar systems (Benner \& Mistry, 2007; Behnke, Piercy, \& Diversi, 2004; Kim, Sherraden, Huang, \& Clancy, 2015), may be more strongly influenced by the intervention of the CSA account. While the 529 account instrument is theoretically available to these families even without a Children's Savings Account structure, low-income families are unlikely to see 529 plans as valuable supports to their objectives of college attainment for their children, evidenced by the concentration of 529 enrollment among economically-advantaged families (United States Government Accountability Office, 2012) and the low proportion (19\%) of low-income college-saving households who report saving in 529 accounts (Sallie Mae, 2016). Prior to conversion to CSAs, 529s might have been seen by lower-income families, if they knew about them at all, as accounts for those unlike them, therefore having no relationship with their own expectations. Conversely, as a platform for 
a CSA intervention, state 529 accounts are augmented to provide easy enrollment, initial deposits, matching, and incentives to encourage lower-income families to participate; these CSA features may help low-income families who now have accounts to see college as more attainable because they now have a way to help pay for it.

Second, among high-income families, having the 529 account through Promise Indiana does not seem to alter their expectations for their children’s college attainment, while the Promise Plus intervention does. This is also consistent with previous literature. SEED OK research found weaker effects on parental expectations for high- rather than for low-income parents (Kim, Sherraden, Huang, \& Clancy, 2015). Other literature finds that the educational expectations of high-income parents are already high and therefore likely less susceptible to influence by an intervention such as provision of an account for college saving (City Trends, 2015). However, even among high-income families, overall rates of saving for college are relatively low and trending downward in national data (SallieMae, 2015). This suggests, with respect to saving for college, even among high-income families, the context does not necessarily signal to begin saving for their child's college education. For these families, then, the additional components of the Promise Plus intervention may serve to make parents more likely to act on what might otherwise be latent expectations, thereby focusing their attention on this element of their children’s futures.

Indeed, qualitative interviews with parents whose children have 529 accounts through Promise Indiana suggest that this may be the case. Marcie is a mother in Jay County whose family earns more than $\$ 100,000$ per year. She described the Promise Plus intervention this way. "We got started because we got the phone calls and the letters that if you start this up, Portland Foundation is going to give you this amount of money. So, we said, "Why not?” and just 
jumpstarted our savings for the kids.” Mom Lindsay, whose family also earns more than $\$ 100,000$ per year, cited as the 'most important' part of the Promise not the matching incentives or even the account itself but, instead, "the involvement in kids and their education and they take them to the college and get them excited about learning beyond high school and open their eyes to degrees and experiments and things at the campus. I think that's more important even than the saving." She said that, since her son started in the Promise, [he] "talks about college more with the exposure to it. I've got younger sisters who've gone through college and he's been able to visit them and see them. Just that whole building that schema of understanding what college is about.”

Finally, the results from this study indicate that the effects of the Promise program and the provision of the CSA were strongest among families with no college. While there is little existing literature to affirm these findings, there are indicators in other research that, together, help to explain these findings. Many of these parents without college degrees are among the lowincome survey respondents, for whom the account may be particularly beneficial, as discussed above. At the same time, those parents with little knowledge about college may benefit particularly from the other elements of the Promise Indiana intervention, including the trips to visit colleges and the assistance understanding college costs and financing. Again, parents speak of Promise Indiana in these terms. Charlotte has a high school diploma and earns less than $\$ 15,000$ per year. She describes the Promise as a "program that's trying to encourage kids to think about their life beyond high school and get parents thinking about how they're going to pay for that, and the kids thinking a little bit about how that's going to work." The financial supports of Promise Indiana are also important to Charlotte, however. She says that receiving the champion incentives have "given [her] hope that financially, they're able to go to college, 
compared to now.” Parents like Charlotte may have had lower expectations prior to the Promise program and account provision, due to their low-income status and other barriers (Kim, Sherraden, \& Clancy, 2013). They may lack critical information about financial aid and college costs (Grodsky \& Jones, 2004; Horn, Chen, \& Chapman, 2003). However, Promise Indiana appears to be reshaping their sense of what is possible for their children.

\section{Limitations}

One potential limitation of examining a community-based intervention is violation of the stable unit treatment value assumption (SUTVA). That is, statistical models assume that cases are independent or that the treatment of one individual does not influence that of another. In this case, individuals exposed to The Promise program could have encouraged others to open a 529 account, discussed college savings, or chatted about expectations for their children's education. However, because we provide a reduced-form estimate of the relationship between The Promise program and parental expectations, these spillovers do not bias our results. Compared to other

CSA research, however, they could slightly change the meaning of our estimates. In other words, while most CSA research estimates the individual effects of receiving a CSA, we are estimating the relationship between exposure to a community-based program and parental expectations. This estimate could include parental communication and encouragement within the community, which may be absent from other CSA programs and research experiments, from which the CSA literature base is derived.

Another limitation is that interaction between having a 529 account and Promise Plus does not fully capture all of the unique aspects of Promise Indiana, particularly in terms of unique adaptations pursued by replicating counties. It only captures whether a family has a 529 
account and was exposed to The Promise program. Further, with regard to having a 529, because the survey only indicates whether or not families have a 529, it is not clear whether they signed up for the account as part of the advertising campaign or had signed up for it prior to Promise Plus. However, there is some evidence that suggests most of the parents in this study likely signed up as a result of the advertising campaign. Among respondents before Promise, only 9 percent report having a 529 account, compared to 34 percent after Promise. Still, the relatively low proportion reporting having a 529 account raises another possible limitation of this study. The savings data from Ascensus, the state 529 provider, shows that more than 3,200 families opened a 529 after the advertising campaign in the Wabash County area (Jones-Layman, 2015). Therefore, despite the marked increase from 9 percent to 34 percent, far fewer survey participants report having a 529 account than the actual savings records indicate.

Apparent under-reporting of 529 account ownership may be due to the low response rates to the survey, which are another limitation of this study. Higher response rates would increase the likelihood that the results generalize to the population. The low response rates might indicate that only certain types of parents responded to the surveys. As a result, the true effects of Promise Indiana may be underestimated here. To partially assess the extent to which nonresponse may underrepresent particular groups, we compared the racial makeup of children in our sample to that of public schools in the counties included in the Promise program and our study. Eighty-six percent of our sample is white, compared to 87 percent in the population. Similarly, 9 percent of our sample, compared to 10 percent of the population, is Hispanic/Latino. Black and Asian or Pacific Islander each make up less than one percent of both our sample and the population. Children in the 'other race' category make up one percent of our sample and 2 
percent of the population. Thus, in terms of child race, our sample is very similar to the public school population in the geographic area studied.

A further limitation is that changes in parental educational expectations could reflect other changes that occurred between the pre- and post-surveys or changes that occur as the child ages. However, the short time period between pre- and post-survey collection limits the extent to which some other change could explain changes in educational expectations. Furthermore, because program rollout and data collection differed by county, any change that could explain the results would have had to occur in 2013 in Wabash County and in 2014 in LaGrange, Noble, and Whitley counties. Controls for child grade level help account for potential changes with age that could explain changes in parental educational expectations. The anonymous nature of the data collection precluded tracking for follow-up; as a result, we are forced to examine group effects rather than effects on specific individuals.

\section{Policy Implications}

Correlational evidence from this study suggests The Promise Program may have an equalizing effect on parental educational expectations by parental education level by exerting greater effects on the educational expectations of less educated parents than those with more education. If additional research finds this is the case, a model such as The Promise may be one policy lever to help increase equality in educational expectations for children. In other words, a CSA program like The Promise Program could be implemented universally, yet help to increase equality of educational expectations between parents with and without college education. Programs with benefits for everyone are more politically appealing and may be more likely to achieve support in state or national legislative bodies. 
Comparing results for low- and high-income families suggests the Promise Program is only associated with higher educational expectations among high-income families. At the same time, however, a 529 account is only associated with higher educational expectations among low-income families. It is possible, therefore, that the aspect of Promise Indiana that matters for parental expectations differs by income. Alternatively, it could be that educational expectations among low-income parents are more difficult to change, requiring policymakers to conceive alternative designs in order to improve expectations among low-income families. 


\section{References}

Aaker, J. and Akutsu, S. (2009). Why do people give? The role of identity in giving. Journal of Consumer Psychology, 19(2009), 267-270.

Assets and Education Initiative [AEDI]. (2013). Building Expectations, Delivering Results: Asset-Based Financial Aid and the Future of Higher Education. In W. Elliott (Ed.), Biannual report on the assets and education field. Lawrence, KS: Assets and Education Initiative (AEDI).

Behnke, A. O., Piercy, K. W., \& Diversi, M. (2004). Educational and occupational aspirations of Latino youth and their parents. Hispanic Journal of Behavioral Sciences, 26(1), 16-35. doi:10.1177/0739986303262329

Benner, A. D., \& Mistry, R. S. (2007). Congruence of mother and teacher educational expectations and low-income youth's academic competence. Journal of Educational Psychology, 99(1), 140-153. doi: http://dx.doi.org/10.1037/0022-0663.99.1.140

Bennett, W. J., \& Wilezol, D. (2013). Is college worth it?: A former United States secretary of education and a liberal arts graduate expose the broken promise of higher education. Thomas Nelson Inc.

Briley, D. A., Harden, K. P., \& Tucker-Drob, E. M. (2014). Child characteristics and parental educational expectations: Evidence for transmission with transaction. Developmental Psychology, 50(12), 2614-2632. doi: http://dx.doi.org/10.1037/a0038094

Butler, S. M., Beach, W. W., \& Winfree, P. L. (2008). Pathways to economic mobility: Key indicators. Washington, DC: Pew Charitable Trusts, Economic Mobility Project.

Child Trends. (2010). Parental expectations for children's academic attainment. Retrieved from http://www.childtrendsdatabank.org/alphalist?q=node/366 
City Trends (2015). Parental expectations for their children’s academic attainment. Data Bank. Retrieved from http://www.childtrends.org/wpcontent/uploads/2012/07/115_Parental_Expectations.pdf

Coomans, G. (2005). The Demography/Education Squeeze in a Knowledge-Based Economy (2000-2020). Institute for Prospective Technological Studies. European Commission. Retrieved 10/18/2013 from http://ftp.jrc.es/EURdoc/eur21573en.pdf.

Elliott, W. (2009). Children's college aspirations and expectations: The potential role of children's development accounts (CDAs). Children and Youth Services Review, 31(2), 274-283. doi:http://dx.doi.org/10.1016/j.childyouth.2008.07.020

Elliott, W. (2013). Small-dollar children’s savings accounts and children’s college outcomes. Children and Youth Services Review, 35(3), 572-585.

Elliott, W. (2015). Building College-Saver Identities among Latino Immigrants: A TwoGeneration Prosperity Kids Account Pilot Program. Lawrence, KS: Center on Assets, Education, and Inclusion.

Elliott, W. and Beverly, S. (2011). The role of savings and wealth in reducing "wilt” between expectations and college attendance. Journal of Children and Poverty, 17(2), 165-185.

Elliott, W., Jung, H., and Friedline, T. (2011). Raising math scores among children in low-wealth households: Potential Benefit of Children’s School Savings. Journal of Income Distribution, 20(2), 72-91.

Elliott, W. and Lewis, M. K. (2015). Transforming 529s into children’s savings accounts (CSAs): The Promise Indiana model. Lawrence, KS: Center on Assets, Education, and Inclusion (AEDI). 
Elliott, W., \& Sherraden, M. (2013). Assets and educational achievement: Theory and evidence. Economics of Education Review, 33, 1-7. doi: http://dx.doi.org/10.1016/j.econedurev.2013.01.004

Elliott, W., Sherraden, M., Johnson, L. and Guo, B. (2010). Young children's perceptions of college and saving: Potential role of child development accounts. Children and Youth Services Review, 32(11), 1577-1584.

Freedman, D. A. (2006). Statistical Models for Causation: What Inferential Leverage Do They Provide? Evaluation Review 30(6), 691-713.

Friedline, T. (2014). The independent effects of savings accounts in children's names on their savings outcomes in young adulthood. Journal of Financial Counseling and Planning, 25(1), 69-89.

Giganti, Mark J., Jens W. Levy, Yolan Banda, Thankian Kusanthan, Moses Sinkala, Jeffrey S.A. Stringer, and Benjamin H. Chi. 2010. "Methods and Baseline Results of a Repeated Cross-Sectional Survey to Assess the Public Health Impact of Antiretroviral Therapy in Lusaka, Zambia.” American Journal of Tropical Medicine and Hygiene 82(5):971-977.

Greenstone, M., \& Looney, A. (2011). Where Is the Best Place to Invest \$102,000: In Stocks, Bonds, or a College Degree?. Washington, DC.: The Brookings Institution. Available at http://www.brookings.edu/papers/2011/0625_education_greenstone_looney.aspx.

Grodsky, E. and Jones, M.T. (2004). Real and Imagined Barriers to College Entry: Perceptions of Cost. Social Science Research 36:745-766.

Hooks, G., C. Mosher, S. Genter, T. Rotolo, \& L. Lobao. 2010. Revisiting the Impact of Prison Building on Job Growth: Education, Incarceration, and County-Level Employment, 1976-2004. Social Science Quarterly 91(1): 228-244. 
Horn, L., Chen, X. and Chapman, C. (2003). Getting Ready to Pay for College: What Students and Their Parents Know About the Cost of College Tuition and What They Are Doing to Find Out. Washington, D.C.: National Center for Education Statistics, Institute of Education Sciences, U.S. Department of Education.

Huang, J., Sherraden, M., \& Purnell, J. Q. (2014). Impacts of Child Development Accounts on maternal depressive symptoms: Evidence from a randomized statewide policy experiment. Social Science \& Medicine, 112, 30-38.

Huang, J., Sherraden, M., Kim, Y., \& Clancy, M. (2014). Effects of child development accounts on early social-emotional development: an experimental test. JAMA pediatrics, 168(3), 265-271.

Kim, Y., Sherraden, M., \& Clancy, M. (2013). Do mothers' educational expectations differ by race and ethnicity, or socioeconomic status? Economics of Education Review, 33, 82-94. doi: 10.1016/j.econedurev.2012.09.007

Kim, Y., Sherraden, M., Huang, J., \& Clancy, M. (2015). Child Development Accounts and parental educational expectations for young children: Early evidence from a statewide social experiment. Social Service Review, 89(1), 99-137. doi: 10.1086/680014

Lewis, M. K. \& Elliott, W. (2015). A regional approach to children’s savings account development: The case of New England. Lawrence, KS: Center on Assets, Education, and Inclusion (AEDI).

Lutz , W., J.C. Cuaresma, and W. Sanderson. 2008. The Demography of Educational Attainment and Economic Growth. Science 319: 1047-8.

Lutz, W. \& K.C. Samir. 2011. Global Human Capital: Integrating Education and Population. Science 333: 587-92. 
Marston, C., H. Meltzer, \& A. Majeed. 2005. “Impact on Contraceptive Practice of Making Emergency Hormonal Contraception Available over the Counter in Great Britain: Repeated Cross Sectional Surveys.” BMJ 331(7511):271.

Moretti, E. 2004. “Estimating the social return to higher education: evidence from longitudinal and repeated cross-sectional data.” Journal of Econometrics 121(1-2):175-212.

Oyserman, D. (2007) Social identity and self-regulation. In A. Kruglanski and T. Higgins (Eds.). Handbook of social psychology (2nd ed.) (pp. 432-453). New York: Guilford Press.

Oyserman, D. (2013). Not just any path: Implications of identity-based motivation for school outcome disparities. Economics of Education Review, 33(1), 179-190.

Oyserman, D. (2015). Identity-based motivation. In R. S. S. Kosslyn (Ed.), Emerging Trends in the Social Sciences.: John Wiley and Sons.

Oyserman, D., and Destin, M. (2010). Identity-based motivation: Implications for intervention. The Counseling Psychologist, 38(7), 1001-1043. doi:10.1177/0011000010374775

Padgett, D. (2008). Qualitative methods in social work research, 2nd, Thousand Oaks, CA: Sage Publications.

Patton, M. (2002). Qualitative evaluation and research methods. London: Sage.

Powell, W.W. \& K. Snellman. 2004. The Knowledge Economy. Annual Review of Sociology 30: 199-220.

Rauscher, E. 2015. “Educational Expansion and Occupational Change: U.S. Compulsory Schooling Laws and the Occupational Structure 1850-1930.” Social Forces 93(4): 13971422. 
Reynolds, J. R., \& Pemberton, J. (2001). Rising college expectations among youth in the United States: A comparison of the 1979 and 1997 NLSY. The Journal of Human Resources, 36(4), 703-726.

Rutchick, A. M., Smyth, J. M., Lopoo, L. M., \& Dusek, J. B. (2009). Great expectations: The biasing effects of reported child behavior problems on educational expectancies and subsequent academic achievement. Journal of Social and Clinical Psychology, 28(3), 392-413.

Sallie Mae. (2016). How America saves for college 2016. Sallie Mae’s National Study of Parents with Children Under Age 18. Conducted by Ipsos Public Affairs. Report. Newark, DE: Sallie Mae. Retrieved from https://salliemae.newshq.businesswire.com/sites/salliemae.newshq.businesswire.com/file s/doc_library/file/HowAmericaSaves2016_FINAL.pdf

Sallie Mae. (2015). How America saves for college 2015. Sallie Mae’s National Study of Parents with Children Under Age 18. Conducted by Ipsos Public Affairs. Report. Newark, DE: Sallie Mae. Retrieved from https://salliemae.newshq.businesswire.com/sites/salliemae.newshq.businesswire.com/file s/doc_library/file/HowAmericaSaves2015_FINAL.pdf

Schuman, T. (2015, February 18). Making a college ‘promise'; community applications available [Blog post]. Retrieved from http://www.indianachamberblogs.com/making-a-collegepromise-community-applications-available/

Sherraden, M. (1991) Assets and the poor: A new American welfare policy. Armonk, NY: M.E. Sharpe. 
Shults, R.A. and L.F. Beck. 2012. “Self-Reported Seatbelt Use, United States, 2002-2010: Does Prevalence Vary by State and Type of Seatbelt Law?” Journal of Safety Research 43(56):417-420.

Spera, C., Wentzel, K. R., \& Matto, H. C. (2009). Parental aspirations for their children's educational attainment: Relations to ethnicity, parental education, children's academic performance, and parental perceptions of school climate. Journal of Youth and Adolescence, 38(8), 1140-1152. doi: 10.2307/ 2295627.

StataCorp. 2013. Stata Statistical Software: Release 13. College Station, TX: StataCorp LP. United States Government Accountability Office [GAO]. (2012, December 12). Higher education: A small percentage of families save in 529 plans. GAO-13-64. Washington, DC: Author

Wang, Y., \& Benner, A. D. (2014). Parent-child discrepancies in educational expectations: differential effects of actual versus perceived discrepancies. Child Development, 85(3), 891-900. doi: 10.1111/cdev.12122

Wells, R., Seifert, T., \& Saunders, D. (2013). Gender and realized educational expectations: The roles of social origins and significant others. Journal of the Association for Institutional Research, 54(6), 599-626. doi: 10.1007/s11162-013-9308-5

Woo, B., Rademacher, I., \& Meier, J. (2010). Upside Down: the \$400 billion federal asset building budget.

Yamamoto, Y., \& Holloway, S. D. (2010). Parental expectations and children's academic performance in sociocultural context. Educational Psychology Review, 22(3), 189-214. doi: 10.1007/s10648-010-9121-z 